\title{
Pelatihan Penggunaan Laboratorium Virtual Bagi Guru IPA dan Matematika di SMP Sepuluh Nopember Sidoarjo
}

\author{
Septi Budi Sartika ${ }^{1)}$, Nur Efendi ${ }^{2)}$, Luluk Iffatur Rocmah ${ }^{3)}$ \\ ${ }^{1,2,3)}$ Universitas Muhammadiyah Sidoarjo \\ septibudi1@umsida.ac.id
}

\begin{abstract}
ABSTRAK: Praktikum atau percobaan merupakan bagian penting dalam pembelajaran IPA. Hal ini juga tidak kalah pentingnya untuk mata pelajaran matematika yaitu untuk simulasi dalam pemahaman konsep matematis yang disampaikan, sebagai bahan untuk latihan lanjutan. Sering kali sekolah mempunyai keterbatasan dalam alat dan bahan untuk kegiatan praktikum, sehingga kegiatan praktikum ditiadakan. Tidak ada alasan untuk tidak melakukan kegiatan praktikum, karena ada laboratorium virtual sebagai upaya pemanfaatan Information Communication Technology (ICT). Laboratorium virtual menggunakan PhET Interactive Simulations. Berdasarkan hasil angket respons guru IPA dan matematika diperoleh: 1) pelatihan yang dilakukan sesuai dengan kondisi saat ini, yaitu kondisi kegiatan belajar dari rumah (Pandemi Covid-19), tidak ada yang tidak mungkin bahwa kegiatan praktikum IPA/ Matematika harus tetap berjalan meski dengan laboratorium virtual baik online maupun offline; 2) guru IPA dan Matematika semangat dalam mengikuti pelatihan, selain dengan antusias dan semangat serta memberikan reaksi positif dengan kesanggupan dalam mengimplementasikan laboratorium virtual pada mata pelajaran yang diajarkan, 3) materi hand out dan daftar aplikasi PhET yang sesuai dengan Kurikulum 2013 pada kompetensi IPA dan Matematika SMP serta bahan ajar untuk implementasi PhET telah membantu guru dalam memahami pelatihan yang disampaikan.
\end{abstract}

Kata Kunci : pelatihan, laboratorium virtual, PhET, IPA, Matematika

ABSTRACT: Practicum or experimentation is an important part of natural science learning. It is also no less important for mathematical subjects i.e. for simulation in understanding the mathematical concepts delivered, as materials for advanced exercises. Often schools have limitations in tools and materials for practical activities, so that practicum activities are eliminated. There is no reason not to do practical activities, because there is a virtual laboratory as an effort to use the Information Communication Technology. Virtual Labs use PhET Interactive Simulations. Based on the results of a response poll and mathematics teachers obtained: 1) training conducted in accordance with the current conditions, namely the condition of learning activities from the home (pandemic Covid-19), there is no unlikely that the activities of natural science practicum/mathematics should continue to run even with a virtual laboratory both online and offline; 2) teachers of natural science and mathematics spirit in the training, in addition to enthusiasm and enthusiasm and positive reaction with the ability to implement a virtual laboratory in the subjects taught, 3) hand out material and a list of the PhET applications in accordance with the curriculum 2013 on the natural science and mathematics competence of SMP and teaching materials for the implementation of PhET has helped teachers understand the training delivered.

Keywords: training, virtual laboratory, PhET, Natural Science, Mathematics

\section{PENDAHULUAN}

SMP Sepuluh Nopember Sidoarjo merupakan sekolah menengah pertama swasta terakreditasi A, yang terletak di Jalan Raya Siwalanpanji, Bedrek, Siwalanpanji, Kecamatan Buduran, Kabupaten Sidoarjo, Jawa Timur 61252. Menurut informasi 
Dapodik (2019), SMP Sepuluh Nopember mempunyai 734 peserta didik, 22 orang guru, dan 6 tenaga kependidikan. Guru IPA sebanyak 5 orang yang mengajar di kelas VII, VIII, dan IX.

Berdasarkan hasil wawancara yang dilakukan dengan Kepala Sekolah sebagai berikut.

$P \quad$ : Bagaimana pembelajaran IPA yang dilakukan di SMP Sepuluh Nopember Sidoarjo selama ini?

KS : Pembelajaran IPA dilakukan sebagaian besar di kelas dan sedikit di laboratorium.

$P \quad: \quad$ Bagaimana media pembelajaran yang digunakan?

KS : Guru menggunakan media sederhana yang digunakan untuk menunjang pembelajaran IPA.

$P \quad: \quad$ Apakah tersedia modul praktikum untuk semua tingkatan kelas?

KS : Modul praktikum ada tetapi masih kurang lengkap.

$P \quad$ : Apakah saat jadwal praktikum selalu di lakukan di laboratorium?

KS : Tidak, sering kali dilakukan di ruang kelas.

Informasi yang diperoleh dari hasil wawancara dengan kepala sekolah, diperoleh pembelajaran IPA banyak dilakukan di kelas sedikit di laboratorium. Laboratorium IPA hanya digunakan untuk praktikum tertentu saja. Kesedian modul praktikum juga minim, sehingga pembelajaran IPA mayoritas berada di kelas dengan sumber belajar guru, buku paket dan buku-buku di perpustakaan.

SMP Sepuluh Nopember Sidoarjo mempunyai 2 laboratorium yaitu Laboratorium IPA dan Laboratorium Komputer. Dengan adanya jumlah komputer yang memadai memungkinkan pembelajaran IPA dengan topik praktikum dapat memanfaatkan komputer untuk laboratorium virtual dapat dilaksanakan dengan baik.

Hasil wawancara dengan kepala sekolah dan guru IPA, diperoleh ada beberapa permasalahan dalam pembelajaran IPA sebagai berikut.

1. Guru membutuhkan alat peraga dan media pembelajaran untuk mengajarkan IPA, terutama materi pembelajaran yang bersifat abstrak, misalnya: atom, energi (listrik, magnet), gaya, dan sebagainya.

2. Pembelajaran IPA mayoritas dilakukan di kelas dan sedikit di laboratorium, hal ini dikarenakan keterbatasan jumlah alat dan bahan serta modul praktikum.

3. Sumber belajar selain guru yaitu buku paket serta buku-buku yang ada di perpustakaan.

4. Guru IPA membutuhkan solusi dalam pembelajaran IPA apapun materi yang disampaikan siswa dapat menemukan konsep baik secara mandiri atau kelompok.

Sujanem, dkk (2019) menyatakan bahwa guru IPA dapat menggunakan media PhET interactive simulations serta mengimplementasikannya di kelas sebagai solusi keterbatasan kegiatan di laboratorium IPA baik ruang, alat, maupun bahan. 
Khaerunnisak (2018), simulasi PhET dapat meningkatkan pemahaman konsep dan motivasi belajar siswa dalam pembelajaran IPA. Sumarauw, dkk (2017) menyatakan bahwa implementasi model inkuiri terbimbing berbantuan PhET dalam pembelajaran IPA dapat meningkatkan hasil belajar siswa baik afektif, kognitif, dan psikomotor. Dengan demikian dapat dinyatakan bahwa media PhET Interactive Simulations dapat digunakan sebagai alternatif solusi dalam pembelajaran IPA.

Solusi yang ditawarkan dalam pemberdayaan guru IPA di SMP Sepuluh Nopember Sidoarjo sebagai berikut.

1. Mengidentifikasi mata praktikum untuk mata pelajaran IPA baik kelas VII, VIII, dan IX, memetakan mata praktikum tersebut ke praktikum nyata atau maya, sehingga keberadaan laboratorium nyata tetap dipergunakan.

2. Mengadakan workshop untuk guru IPA dengan menggunakan laboratorium virtual PhET interactive simulations.

3. Melakukan pengamatan efektivitas pembelajaran IPA dengan PhET interactive simulations, meliputi: keterlaksanaan pembelajaran IPA dengan PhET Interactive Simulations; aktivitas siswa, peningkatan pemahaman konsep IPA, dan respon siswa.

\section{PERMASALAHAN}

Hasil wawancara dengan kepala sekolah dan guru IPA, diperoleh ada beberapa permasalahan dalam pembelajaran IPA antara lain sebagai berikut.

1. Guru membutuhkan alat peraga dan media pembelajaran untuk mengajarkan IPA, terutama materi pembelajaran yang bersifat abstrak, misalnya: atom, energi (listrik, magnet), gaya, dan sebagainya.

2. Pembelajaran IPA mayoritas dilakukan di kelas dan sedikit di laboratorium, hal ini dikarenakan keterbatasan jumlah alat dan bahan serta modul praktikum.

3. Sumber belajar selain guru yaitu buku paket serta buku-buku yang ada di perpustakaan.

4. Guru IPA membutuhkan solusi dalam pembelajaran IPA apapun materi yang disampaikan siswa dapat menemukan konsep baik secara mandiri atau kelompok.

\section{METODE PELAKSANAAN}

Kegiatan pengabdian kepada masyarakat kemitraan institusi ini akan dilakukan dengan 3 tahapan, yaitu.

1. Tahap Perencanaan

Tahap ini dimulai dari hasil wawancara dengan kepala sekolah dan guru IPA tentang pembelajaran IPA yang berlangsung di kelas, guru merasa kesulitan untuk mengajarkan IPA dengan media pembelajaran yang selama ini digunakan. Dengan memperhatikan hal tersebut muncul rencana untuk melakukan pelatihan bagi guru 
IPA di SMP Sepuluh Nopember Sidoarjo dengan menggunakan laboratorium virtual PhET Interactive Simulations.

2. Tahap Pelaksanaan

Tahap ini dimulai dari pemetaan mata praktikum nyata dan maya, melakukan workshop penggunaan PhET interactive simulations, dan melakukan pengamatan efektivitas pembelajaran IPA dengan PhET Interactive Simulations.

3. Tahap Pelaporan.

Tahap ini dimulai dengan penyusunan laporan per kegiatan, selanjutnya penyusunan artikel dan dipublikasikan ke jurnal abdimas, Buku Panduan Aplikasi PhET dan Pemetaan Materi IPA dan Matematika di SMP, dan artikel yang dimuat di media massa.

\section{PELAKSANAAN}

Pelaksanaan kegiatan abdimas selama 6 bulan, yaitu dimulai bulan Januari sampai dengan Juni 2020 di SMP Sepuluh Sidoarjo Jawa Timur.

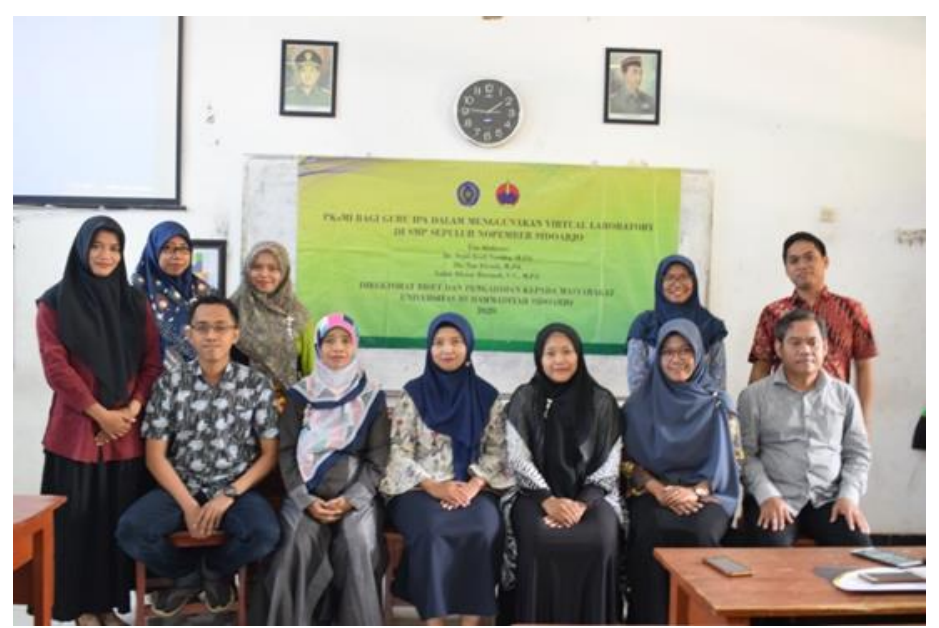

Gambar 1. Pelaksanaan Kegiatan beserta para peserta

\section{HASIL DAN LUARAN}

Hasil dari kegiatan pengabdian kepada masyarakat bagi kemitraan institusi ini sebagai berikut:

1. Pemetaan Materi IPA dan Matematika SMP sesuai dengan Kompetensi Dasar SMP di Kurikulum 2013.

Tabel 1. Pemetaan Mata Praktikum IPA sesuai Kurikulum 2013

\begin{tabular}{clll}
\hline No & \multicolumn{1}{c}{ Nama Mata Praktikum } & Kelas/Sem & \multicolumn{1}{c}{ Ket File } \\
\hline 1 & Massa Jenis & VII/1 & Flash \\
\hline 2 & Perpindahan Kalor secara Konduksi & VII/1 & Java
\end{tabular}




\begin{tabular}{|c|c|c|c|}
\hline No & Nama Mata Praktikum & Kelas/Sem & Ket File \\
\hline 3 & Bentuk dan Perubahan Energi & $\mathrm{VII} / 1$ & Java \\
\hline 4 & Energi: Skate Dasar & VII/1 & Java \\
\hline 5 & Energi: Skate Board Lengkung & VII/1 & Java \\
\hline 6 & Efek Rumah Kaca (green house effect) & $\mathrm{VII} / 2$ & Java \\
\hline 7 & Lempeng Tektonik & $\mathrm{VII} / 2$ & Java \\
\hline 8 & Sistem Tata Surya & $\mathrm{VII} / 2$ & Flash \\
\hline 9 & Gravitasi dan Orbit & $\mathrm{VII} / 2$ & Flash \\
\hline 10 & Gaya dan Gerak (dasar) & VIII/1 & Java \\
\hline 11 & Gerak (2 dimensi) & VIII/1 & Java \\
\hline 12 & Gaya dan Gerak pada Bidang Datar & $\mathrm{VIII} / 1$ & Java \\
\hline 13 & Gaya dan Gerak pada Bidang Miring & VIII/1 & Java \\
\hline 14 & Bidang Miring & VIII/1 & Java \\
\hline 15 & Tuas & VIII/1 & Java/Flash \\
\hline 16 & Wujud Zat & $\mathrm{VIII} / 2$ & Java \\
\hline 17 & Tekanan Gas & $\mathrm{VIII} / 2$ & Java \\
\hline 18 & Tekanan Air & $\mathrm{VIII} / 2$ & Java \\
\hline 19 & Bandul sederhana & $\mathrm{VIII} / 2$ & Java \\
\hline 20 & Gelombang pada tali & $\mathrm{VIII} / 2$ & Java/Flash \\
\hline 21 & Massa dan Pegas & $\mathrm{VIII} / 2$ & Java \\
\hline 22 & Resonansi & $\mathrm{VIII} / 2$ & Java/Flash \\
\hline 23 & Gelombang Radio & $\mathrm{VIII} / 2$ & Java \\
\hline 24 & Gelombang Suara & $\mathrm{VIII} / 2$ & Java \\
\hline 25 & Tampilan Warna Cahaya & $\mathrm{VIII} / 2$ & Java \\
\hline 26 & Optika Geometri & $\mathrm{VIII} / 2$ & Java/Flash \\
\hline 27 & Pembiasan/ Pembelokan Cahaya & $\mathrm{VIII} / 2$ & Java \\
\hline 28 & Seleksi Alam & $\mathrm{IX} / 1$ & Java \\
\hline 29 & Balon dan Listrik Statis & $\mathrm{IX} / 1$ & Java \\
\hline 30 & Pembangkit Listrik Statis John Travoltage & IX/1 & Java \\
\hline 31 & Gambaran Medan Listrik & IX/1 & Java \\
\hline 32 & Hukum Ohm & $\mathrm{IX} / 1$ & Java \\
\hline 33 & Rangkaian Listrik DC & $\mathrm{IX} / 1$ & Java \\
\hline 34 & Rangkaian Baterai-Resistor & $\mathrm{IX} / 1$ & Java \\
\hline 35 & Muatan dan Medan Listrik & IX/1 & Java \\
\hline 36 & Magnet dan Elektromagnet & $\mathrm{IX} / 2$ & Java \\
\hline 37 & Magnet dan Kompas & $\mathrm{IX} / 2$ & Java \\
\hline 38 & Atom & $\mathrm{IX} / 2$ & Java \\
\hline 39 & Molekul & $\mathrm{IX} / 2$ & Java \\
\hline 40 & Bentuk Molekul Dasar & $\mathrm{IX} / 2$ & Java \\
\hline
\end{tabular}


Tabel 2. Pemetaan Mata Praktikum Matematika sesuai Kurikulum 2013

\begin{tabular}{clll}
\hline No & \multicolumn{1}{c}{ Judul Praktikum } & Kelas/Sem & \multicolumn{1}{c}{ Ket File } \\
\hline 1 & Pendahuluan Pecahan & VII/1 & Java \\
\hline 2 & Membuat Pecahan & VII/1 & Java \\
\hline 3 & Persamaan Pecahan & VII/1 & HTML version \\
\hline 4 & Persamaan Pecahan Campuran & VII/1 & HTML version \\
\hline 5 & Model Desimal & VII/1 & HTML version \\
\hline 6 & Pecahan Senilai dan Pecahan Campuran & VII/1 & Java \\
\hline 7 & Garis Bilangan: Bilangan Bulat & VII/1 & HTML version \\
\hline 8 & Model Aljabar & VII/1 & HTML version \\
\hline 9 & Persamaan Linier (Dasar) & VII/1 & HTML version \\
\hline 10 & Persamaan Linier 1 Variabel & VII/1 & HTML version \\
\hline 11 & Rasio & VII/2 & HTML version \\
\hline 12 & Proporsi & VII/2 & HTML version \\
\hline 13 & Aritmatika & VII/2 & Flash/HTML version \\
\hline 14 & Menggambar Garis & VIII/1 & Java \\
\hline 15 & Grafik Persamaan & VIII/1 & Flash/HTML version \\
\hline 16 & Membuat Fungsi & VIII/1 & HTML version \\
\hline 17 & Membuat Fungsi (Dasar) & VIII/1 & HTML version \\
\hline 18 & Grafik Fungsi Linier & VIII/1 & HTML version \\
\hline 19 & Gradien & VIII/1 & HTML version \\
\hline 20 & Persamaan Linier 2 Variabel & VIII/1 & HTML version \\
\hline 21 & Statistika Peluang & VIII/2 & HTML version \\
\hline 22 & Estimasi & VIII/2 & HTML version \\
\hline 23 & Grafik Fungsi Kuadrat & IX/1 & HTML version \\
\hline & & & \\
\hline
\end{tabular}

2. Angket Respons Guru dalam penggunaan laboratorium penggunaan laboratorium virtual berbasis aplikasi PhET Interactive Simulations menggunakan google form.

Tabel 3. Pernyataan Respons Guru terhadap Pelatihan

\begin{tabular}{ll}
\hline No & \multicolumn{3}{c}{ Pernyataan Respons Guru } \\
\hline 1 & $\begin{array}{l}\text { Saya mengikuti pelatihan berdasarkan kesesuaian topik pelatihan dengan mata } \\
\text { pelajaran yang saya ajarkan. }\end{array}$ \\
\hline 2 & Saya mengikuti pelatihan karena topik sesuai dengan kondisi saat ini. \\
\hline 3 & Saya antusias dan semangat saat mengikuti pelatihan. \\
\hline 4 & Saya merasa pelatihan memberikan penyegaran pikiran yang jenuh. \\
\hline 5 & Saya berpikir pelatih memiliki konsep dasar keilmuan yang sesuai. \\
\hline 6 & $\begin{array}{l}\text { Saya rasa pelatih memiliki wawasan yang luas terhadap materi yang } \\
\text { disampaikan. }\end{array}$ \\
\hline 7 & Pelatih mempunyai kemampuan penyesuaian diri terhadap peserta pelatihan. \\
\hline 8 & Pelatih bersikap ramah dan sopan dalam menjawab pertanyaan peserta pelatihan. \\
\hline
\end{tabular}




\begin{tabular}{ll}
\hline No & \multicolumn{1}{c}{ Pernyataan Respons Guru } \\
\hline 9 & $\begin{array}{l}\text { Pelatih mampu mentransfer materi kepada peserta pelatihan sehingga sasaran } \\
\text { yang diinginkan tercapai. }\end{array}$ \\
\hline 10 & Pelatih mampu menunjukkan sikap santun dalam menyampaikan materi. \\
\hline 11 & Saya merasa nyaman di ruang pelatihan. \\
\hline 12 & $\begin{array}{l}\text { Saya merasa sarana laptop, hand out, dan LCD projector dapat menunjang } \\
\text { kegiatan pelatihan. }\end{array}$ \\
\hline 13 & $\begin{array}{l}\text { Saya mendapat materi pelatihan berupa hand out dan aplikasi PhET yang } \\
\text { diberikan sesuai dengan kompetensi siswa SMP. }\end{array}$ \\
\hline 14 & $\begin{array}{l}\text { Saya merasa penggunaan laboratorium virtual yang diberikan sesuai dengan } \\
\text { kebutuhan mata pelajaran yang saya ajarkan. }\end{array}$ \\
\hline 15 & Saya mendapat reaksi positif sebagai peserta setelah mengikuti pelatihan. \\
\hline 16 & Saya mampu menyerap materi yang diberikan setelah mengikuti pelatihan. \\
\hline 17 & $\begin{array}{l}\text { Saya akan mengimplementasikan hasil pelatihan ke dalam mata pelajaran yang } \\
\text { saya ajarkan. }\end{array}$ \\
\hline
\end{tabular}

Berdasarkan Tabel 3, diperoleh bahwa guru memberikan respons positif terhadap kegiatan pelatihan, hal ini dibuktikan dengan lebih dari 50\% guru memberikan skor 4 dan 5 pada tiap butir pernyataan. Dengan demikian, dapat dikatakan bahwa;

a. Pelatihan yang dilakukan sesuai dengan kondisi saat ini, yaitu kondisi kegiatan belajar dari rumah (Pandemi Covid-19), tidak ada yang tidak mungkin bahwa kegiatan praktikum IPA atau Matematika harus tetap berjalan meski dengan laboratorium virtual baik online maupun offline.

b. Guru IPA dan Matematika semangat dalam mengikuti pelatihan, selain dengan antusias dan semangat serta memberikan reaksi positif dengan kesanggupan dalam mengimplementasikan laboratorium virtual pada mata pelajaran yang diajarkan.

c. Materi hand out dan daftar aplikasi PhET yang sesuai dengan Kurikulum 2013 pada kompetensi IPA dan Matematika SMP serta bahan ajar untuk implementasi PhET telah membantu guru dalam memahami pelatihan yang disampaikan.

\section{KESIMPULAN}

Berdasarkan hasil kegiatan yang telah dicapai, dapat disimpulkan sebagai berikut.

1. Aplikasi PhET sangat sesuai digunakan sebagai alternatif pengganti praktikum nyata. Aplikasi ini bisa digunakan baik secara online maupun offline.

2. Untuk kelancaran kegiatan praktikum dengan menggunakan laboratorium virtual adalah perencanaan yaitu perancangan bahan ajar yang di dalamnya berupa LKS untuk memnadu siswa dalam melakukan praktikum maya serta instal aplikasi PhET di komputer di laboratorium Komputer atau menggunakan wifi. 
3. Perancangan bahan ajar praktikum maya perlu dilakukan supaya siswa tidak bingung dalam memahami konsep IPA atau Matematika yang disampaikan.

\section{DAFTAR PUSTAKA}

Khaerunnisak, K. 2018. Peningkatan Pemahaman Konsep dan Motivasi Belajar Siswa melalui Simulasi Physic Education Technology (PhET). Jurnal Penelitian Pendidikan IPA, 4(2).

McLelland, C. V. 2003. The Nature of Science and The Scientific. The Geological Society of America.

Sumarauw, J. M., Ibrahim, M., \& Prastowo, T. 2017. Pengembangan Perangkat Pembelajaran Berbasis Inkuiri Terbimbing Berbantuan Simulasi PhET Dalam Pembelajaran IPA. Jurnal Penelitian Pendidikan, 34(1); p. 25-36.

Sujanem, R., Sutarno, E., \& Gunadi, I. G. A. 2019. Pelatihan dan Pendampingan Pembuatan Media Simulasi Praktikum IPA SMP dengan Program Simulasi PhET. International Journal of Community Service Learning, 3(1); p. 11. 